\title{
Decreased cutaneous vasodilatation to isometric handgrip exercise in Alzheimer's disease
}

\author{
János Kálmán ${ }^{1 *}$, Réka Szakács ${ }^{1}$, Tamás Török ${ }^{2}$, Zsuzsa Rózsa ${ }^{3 \dagger}$, Pál Barzó ${ }^{4}$, \\ László Rudas ${ }^{2}$, J. Gy. Papp ${ }^{3}$ and Zoltán Janka ${ }^{1}$ \\ ${ }^{1}$ Department of Psychiatry, University of Szeged, Hungary \\ ${ }^{2}$ Medical Intensive Care Unit, University of Szeged, Hungary \\ ${ }^{3}$ Department of Pharmacology, University of Szeged, Hungary \\ ${ }^{4}$ Department of Neurosurgery, University of Szeged, Hungary
}

\section{SUMMARY}

Background Cutaneous active vasodilatation is a cholinergic nerve mediated function of the sympathetic nervous system and the disturbed function of cholinergic neurotransmission is known as a prominent feature of Alzheimer's disease (AD). Methods To assess this relationship, skin blood flow (SkBF) and other haemodynamic parameters were determined by a simple vasodilatory test, isometric handgrip exercise (IHG), in 22 late-onset sporadic type AD and 20 aged control persons (AC). Results Significantly higher cutaneous vascular resistance and decreased SkBF were found after the stimulus in the AD group. A smaller reduction $(p<0.03)$ of $\mathrm{R}$ wave intervals on the electrocardiogram was observed in the AD group compared to the $\mathrm{AC}$ one. After IHG, change in systolic blood pressure was less in the $\mathrm{AD}(p<0.01)$ than in the AC group.

Conclusion Our results suggest that autonomic dysfunction affecting active vasodilator sympathetic, as well as parasympathetic functions is present in AD. Copyright (C) 2002 John Wiley \& Sons, Ltd.

KEY WORDS - Alzheimer's disease; skin vessel reactivity; isometric handgrip exercise; blood flow

\section{INTRODUCTION}

Several lines of evidence indicate that the autonomic nervous system is affected in Alzheimer's disease (AD). Hypotension and disturbed circadian rhythm of blood pressure (BP) were found to be associated with this type of dementia (Otsuka et al., 1990; Burke et al., 1994; Guo et al., 1996). Thermoregulatory dysfunction has also been reported in AD (Printz et al., 1984; Diamond and Diamond, 1991). In addition, AD patients displayed an impairment in noradrenergic response to orthostasis (Jhee et al., 1995) and

\footnotetext{
*Correspondence to: Dr J. Kálmán, Department of Psychiatry,
University of Szeged, Semmelweis u. 6., H-6725 Szeged, Hungary.

*Correspondence to: Dr J. Kálmán, Department of Psychiatry, Tel: +36 62545 944. Fax: +3662545973.

E-mail: jkalman@nepsy.szote.u-szeged.hu ${ }^{\dagger}$ deceased

Contract/grant sponsor: Health Scientific Board ETT, Hungary. Contract/grant number: 01917/2000.
}

attenuated skin vascular response to cholinergic substances iontophoresed into the skin has been observed (Algotsson et al., 1995). These vasoregulatory disturbances are consistent with the finding, that the central neurons regulating $\mathrm{BP}$ degenerate in $\mathrm{AD}$ (Burke et al., 1994). Autonomic, cholinergic and other brainstem nuclei (e.g. parabrachial nucleus involved in homeostatic control and integration of visceral information) were also found to be affected in AD (Parvizi et al., 2001). These findings could also support the autonomic dysfunctions in patients with $\mathrm{AD}$, including parasympathetic as well as sympathetic cardiovascular alterations. Cutaneous active vasodilatation is a cholinergic nerve mediated function of the sympathetic nervous system. However, there has been no information available on the active skin vasoregulatory function of $\mathrm{AD}$ patients. A simple method, the isometric handgrip exercise (IHG) (Taylor et al., 1989) was used in the present study to examine this function. 


\section{SUBJECTS AND METHODS}

\section{Subjects}

Twenty-two patients with a diagnosis of probable AD and 20 healthy aged control (AC) subjects with similar age and sex distributions participated in the study. All AD probands were selected from the in- and outpatient units of the local memory clinic. The AC subjects were recruited from elderly persons belonging to the hospital staff and from healthy elderly people from the community. The clinical diagnosis of AD was based on the Diagnostic and Statistical Manual of Mental Disorders (DSM-IV; APA, 1994) and NINCDS-ADRDA (McKhann et al., 1984) criteria. Work-ups included the subjects' physical, psychiatric and family history, neurological and psychiatric examination, routine laboratory tests (including thyroid function tests), neuroimaging (cerebral computerized tomography (CT) or magnetic resonance imaging (MRI), electrocardiography, electroencephalography and psychometric evaluations: the MiniMental State Exam (MMSE; Folstein et al., 1975) and the Cued Recall Test (CRT; Grober and Buschke, 1987). The subjects' characteristics are presented in Table 1. All subjects were Caucasian, non-smokers and they were not on medication which alter skin vessel reactivity. Probands with a history or sign of psychiatric disorder, malignancy, diabetes mellitus, hypertension, skin, cerebro- and cardiovascular disease were excluded from further investigations. Other selection criteria were not used to select or subgroup the $\mathrm{AD}$ probands. Before each measurement with a new proband, a 'trial probe' was included in order to assess the proband's capacity to cooperate. There were severely demented AD subjects, who could not cooperate during the experiment therefore they were excluded from further participation. Informed consent was obtained from all probands and, if appropiate, from family members or caregivers. The study

Table 1. Clinical characteristics and neurodiagnostic test scores of probands

\begin{tabular}{lcc}
\hline & $\begin{array}{c}\text { Control subjects } \\
(n=20)\end{array}$ & $\begin{array}{c}\text { Alzheimer patients } \\
(n=22)\end{array}$ \\
\hline Age (years) & $72.0 \pm 6.3$ & $72.9 \pm 6.5$ \\
Male/female & $6 / 14$ & $8 / 14$ \\
Age of onset (years) & - & $66.9 \pm 7.4$ \\
MMSE score & $29.0 \pm 0.9$ & $19.0 \pm 6.5^{*}$ \\
CRT-I. score & $25.3 \pm 2.5$ & $11.4 \pm 6.3^{\#}$ \\
CRT-II. score & $22.0 \pm 3.0$ & $16.5 \pm 9.2$ \\
\hline
\end{tabular}

Data are mean $\pm \mathrm{SD}$; chi-square test: $* p<0.000 ;{ }^{*} p<0.007$; MMSE $=$ Mini-Mental State Examination; CRT-I. $=$ Cued Recall Test, free recall; CRT-II. $=$ Cued Recall Test, cued recall . protocol was approved by the local Human Biomedical Research Ethics Committee.

\section{Experimental procedure}

All measurements were performed between 2:00 and 5:00 pm, in the same room at constant temperature. All probands were left for $30 \mathrm{~min}$ in a supine resting position to acclimatize them to the surroundings before the start of the measurements. Mean arterial blood pressure (MAP), systolic and diastolic blood pressure (DBP and SBP), skin blood flow (SkBF) and skin temperature were monitored continuously in the same position, attached to the ventral side of nonexercising forearm. Blood pressure recordings were made on the 3rd finger of the nonexercising hand placed at heart level. SkBF was measured by means of a double-channel laser-Doppler perfusion monitor (Perimed, Stockholm, Sweden) attached to the ventral side of the non-dominant, non-exercising forearm. A Finapres 2300 (Ohmeda) non-invasive blood pressure monitor was used to measure BP continuously on the same side. ECG was monitored with a Sirecust 730 (Siemens, Germany) monitor. The signals of ECG ( $R$ wave) plethysmograph were amplified and filtered to an analog signal by a digital converter. All data were collected and stored in an IBM-AT compatible computer. Maximal voluntary contraction (VC) was determined by an exercise dynamometer. No differences were observed in the strength of the VC between the groups. Thirty percent of maximal VC, monitorized by exercise dynamometer, was used for $2 \mathrm{~min}$ to perform the isometric handgrip exercise (IHG). The same procedure was repeated twice more with 2 min resting periods between the measurements.

\section{Data analysis}

MAP was calculated as the sum of diastolic blood pressure $+1 / 3$ of the pulse pressure. Skin blood flow was expressed as percentage of maximal skin blood flow. Cutaneous vascular resistance (CVR) was calculated as MAP/SkBF. The change in CVR (dCVR) was calculated according to $\mathrm{dCVR}=(\mathrm{CVRmax}-$ CVRbase)/CVRbase, where base values were measured before IHG and maximal (max) values during the test. Differences between mean values were examined by Student $t$-test for continuous variables (age of probands and haemodynamic parameters) and chisquare test was used for non-parametric values (test scores). All the parametric data had normal distribution. Statistics was calculated with SPSS program. Significance levels were set at $p<0.05$. 
Table 2. Changes of various haemodynamic parameters to isometric handgrip exercise

\begin{tabular}{|c|c|c|c|c|}
\hline & $\begin{array}{l}\text { Control } \\
\text { subjects } \\
(n=20)\end{array}$ & $\begin{array}{l}\text { Alzheimer } \\
\text { patients } \\
(n=22)\end{array}$ & & \\
\hline $\mathrm{dRR}(\mathrm{ms})$ & $-162 \pm 94.9$ & $-108 \pm 51.4$ & $t=2.32$ & $p<0.025$ \\
\hline $\begin{array}{l}\text { dMAP } \\
(\text { Hgmm })\end{array}$ & $37 \pm 16$ & $31 \pm 12$ & & \\
\hline $\begin{array}{l}\text { dSBP } \\
\text { (Hgmm) }\end{array}$ & $48 \pm 17$ & $35 \pm 12$ & $t=2.79$ & $p<0.009$ \\
\hline $\begin{array}{l}\text { dDBP } \\
(\mathrm{Hgmm})\end{array}$ & $29 \pm 12$ & $25 \pm 12$ & & \\
\hline $\operatorname{SkBF}(\%)$ & $25 \pm 33.1$ & $5 \pm 25.2$ & $t=2.02$ & $p<0.05$ \\
\hline dCVR & $0.08 \pm 0.419$ & $0.32 \pm 0.288$ & $t=2.18$ & $p<0.035$ \\
\hline
\end{tabular}

$\mathrm{dRR}, \mathrm{R}$ wave interval changes from the electrocardiogram; dMAP, mean blood pressure changes; dSBP, systolic blood pressure changes; dDBP, diastolic blood pressure changes; dCVR, changes in cutaneous vascular resistance; SkBF, skin blood flow (\% of maximal skin blood flow); Hgmm, millimeters of Mercury. Data are mean \pm SD. Students $t$-test was applied.

\section{RESULTS}

A reduction of $\mathrm{R}$ wave intervals as a result of IHG was observed in both groups (Table 2), but the decrease was significantly smaller in the $A D$ than in the $A C$ group. The static exercise increased changes in both systolic blood pressure (dSBP) and diastolic blood pressure (dDBP) in all groups, but the dSBP was significantly smaller in AD patients than in the controls. The increase of SkBF was significantly smaller in the case of AD probands, and significantly higher dCVR was calculated for the same group. The resting $\mathrm{R}$ wave interval value from the ECG (RR) correlated significantly with the severity of dementia (MMSE score) $(r=0.662 ; p<0.004)$. A highly significant negative correlation $(r=-0.711 ; p<0.001)$ was calculated for the resting $\mathrm{SkBF}$ with the age of all probands.

\section{DISCUSSION}

The human nonglabrous SkBF is known to be regulated by the sympathetic vasoconstrictor and vasodilatator system. Active vasoconstrictor nerves secrete norepinephrine acting on postsynaptic $\alpha_{1}$ and $\alpha_{2}$ receptors (Lindblad and Ekenvall, 1986). On the other hand, cutaneous active vasodilatation has been proven to be mediated by cholinergic nerve cotransmission (Kellogg et al., 1995; Rowell, 1977).

The main observation of this study is that the AD patients have impaired skin vasodilatory function, and this impairment could be revealed with a simple muscle exercise test. Our results support the findings of Algotsson et al. (1995a), who observed a significantly decreased skin vessel reactivity after local, iontophoretical administration of cholinergic agents. Interestingly, the $\mathrm{AD}$ patients possessing the apolipoprotein E $\varepsilon 4$ allele (ApoE4) displayed enhanced vascular reactivity to the iontophoretic acetylcholine (Algotsson et al., 2000). Recent evidence indicates that ApoE4 is linked to AD (Kálmán et al., 1997; Poirier, 1999), supporting the possibility that dysfunctions of the lipid transport system and/or other membrane abnormalities are associated with the AD process. The present investigation has provided further analysis of vascular responses in $\mathrm{AD}$ and proved that impaired skin vessel vasodilatation (decreased $\mathrm{dSkBF}$ and increased dCVR) is present during such a physiological activity as IHG. These results indicate that the autonomic part of the cholinergic system is affected in $\mathrm{AD}$ and that the functional vascular abnormalities are not restricted to cerebral microvasculature.

The change in CVR response to IHG is considered as a result of various neural and humoral effects (Crandall et al., 1995; Kellogg et al., 1995). This vasodilatation is presumably mediated by cholinergic sympathetic mechanism, although the response is greatly influenced by other factors, such as coinciding thermal stimulus (Crandall et al., 1995). Among the $\mathrm{AC}$, an exercise-induced increase in the cutaneous blood flow was documented in this study. With the simultaneous increase of BP, the changes in the calculated CVR were negligible. In contrast, the SkBF response of $\mathrm{AD}$ patients was limited, with a definite increase in calculated CVR. Systemic arterial pressures were not different between the two groups, suggesting that the changes in cutaneous blood flow during IHG are due to local vasomotor abnormalities in $\mathrm{AD}$. We suppose that the response of the $\mathrm{AD}$ patients reflects an opposed vasoconstrictor i.e. defective vasodilation mechanism. It is pertinent to mention here that the acetylcholine induced vasodilation is known to be mediated by endothelium-derived relaxing factors, such as nitric oxide (NO) (Crandall et al., 1995). Furthermore, it has been proven that the process of aging progressively reduces both endothelium-derived NO production in experimental animals (Broten et al., 1992) and endothelium dependent vasodilatation in forearm resistance vessels in humans (Gerhard et al., 1995). Therefore the impaired cutaneous vasodilatation of $\mathrm{AD}$ probands could be the consequence of disturbed cholinergic function and/or altered production of endothelium derived NO. Our results do not permit the localization of the disturbances however. The finding, that the AD probands displayed altered sympathovagal tone 
(having decreased dRR intervals after the IHG test), reflects that the central autonomic control of cardiac function is also affected in AD. These results confirm the findings of Elmstahl et al. (1992), Aharon-Peretz et al. (1992) and Algotsson et al. (1995a, 1995b) using a different experimental approach. Alterations of RR intervals are considered as a marker of the function of the parasympathetic nervous system regulated by the dorsal vagal nucleus (Aharon-Peretz et al., 1992).

In summary, the results of the present study provide further evidence that the autonomic nervous system is impaired in AD. The IHG test could be a useful monitor to follow these alterations over time.

\section{ACKNOWLEDGEMENTS}

The authors gratefully acknowledge the participation of all persons involved in the study. This work was supported by grant Health Scientific Board ETT 01917/2000, Hungary.

\section{REFERENCES}

Aharon-Peretz J, Harel T, Revach M, Ben-Haim S. 1992. Increased sympathetic and decreased parasympathetic cardiac innervation in patients with Alzheimer's disease. Arch Neurol 49: 919-922.

Algottson A, Nordberg A, Almkvist O, Winblad B. 1995a. Skin vessel reactivity is impaired in Alzheimer's disease. Neurobiol Aging 16: 577-582.

Algottson A, Viitanen M, Winbald B, Solders G. 1995b. Autonomic dysfunction in Alzheimer's disease. Acta Neurol Scand. 91: 14-18.

Algottson A, Nordberg A, Winblad B. 2000. Apolipoprotein E $\varepsilon 4$ has an impact on vascular reactivity in Alzheimer's disease. Arch Gerontol Geriatr 31: 221-231.

American Psychiatric Association. 1994. Diagnostic and Statistical Manual of Mental Disorders, 4th edn, revised. APA: Washington, DC.

Broten TPJ, Miyashiro JK, Moncada S, Feigl EO. 1992. Role of endothelium derived relaxing factor in parasympathetic coronary vasodilatation. Am J Physiol 262: R1127-R1137.

Burke WJ, Coronado PG, Schmitt CA, Gillespie KM, Chung HD. 1994. Blood pressure regulation in Alzheimer's disease. J Auton Nerv Syst 48: 65-71.

Crandall CG, Musick J, Hatch JP, Kellogg DL, Johnson JM. 1995. Cutaneous vascular and sudomotor responses to isometric exercise in humans. J Appl Physiol 76: 1946-1950.
Diamond P, Diamond M. 1991. Thermoregulatory behavior in Alzheimer's disease. Lett. to the editor. J Am Geriatr Soc 39: 532 .

Elmstahl S, Petersson M, Lilja B, Samuelsson SM, Rosen I, Bjuno L. 1992. Autonomic cardiovascular responses to tilting in patients with Alzheimer's disease and in healthy elderly women. Age and Aging 4: 301-307.

Folstein MF, Folstein ME, McHugh PR. 1975. 'Mini-Mental State': a practical method for grading the cognitive state of patients for the clinician. J Psychiat Res 12: 189-198.

Gerhard M, Roddy MA, Creager SJ, Creager MA. 1995. Aging progressively impairs endothelium-dependent vasodilation in forearm resistance vessels of humans. Hypertension 27: 849-853.

Grober E, Buschke H. 1987. Genuine memory deficits in dementia. Dev Neuropsychol 3: 13-36.

Guo Z, Viitanen M, Fratiglioni L, Winblad B. 1996. Low blood pressure and dementia in elderly people: the Kungsholmen project. BMJ 312: 805-808.

Jhee SS, Sramek JJ, Wardle TS, Cutler NR. 1995. Orthostasis in Alzheimer disease: a retrospective analysis. Alzheimer Dis Assoc Disord 9: 243-246.

Kálmán J, Juhász A, Császár A, Kanka A, Maglóczky E, Bencsik K, Janka Z, Raskó I. 1997. Apolipoprotein E allele frequencies in patients with late-onset sporadic Alzheimer's dementia in Hungary. Acta Neurol Scand 95: 56-59.

Kellogg DL, Pergola PE, Piest KL, Kosiba WA, Crandall CG, Grossmann M, Johnson JM. 1995. Cutaneous active vasodilation in humans is mediated by cholinergic nerve cotransmission. Circ Res 77: 1222-1228.

Lindblad LR, Ekenvall L. 1986. Alpha-adrenoreceptors in the vessels of human finger skin. Acta Physiol Scand 128: 219-222.

McKhann G, Drachman D, Folstein M, Katzman R, Price D, Stadlan EM. 1984. Clinical diagnosis of Alzheimer's disease: report of the NINCDS-ADRDA Work Group under the auspices of Department of Health and Human Services Task Force on Alzheimer's disease. Neurology 34: 939-944.

Otsuka A, Mikami H, Katahira K, Nakamoto Y, Minamitani K, Imaoka M, Nishide M, Ogihara T. 1990. Absence of nocturnal fall in blood pressure in elderly persons with Alzheimer-type dementia. J Am Geriatr Soc 38: 973-978.

Parvizi J, Van Hoesen GW, Damasio A. 2001. The selective vulnerability of brainstem nuclei to Alzheimer's disease. Ann Neurol 49: $53-66$.

Poirier J. 1999. Apolipoprotein E: A pharmacogenetic target for the treatment of Alzheimer's disease. Mol Diagn 4: 335-341.

Printz PN, Christie FNP, Smallwood BA, Vitaliano P, Bokan J, Vitiello MV, Martin D. 1984. Circadian temperature variation in healthy aged and in Alzheimer's disease. J Gerontol 39: $30-35$.

Rowell LB. 1977. Reflex control of the cutaneous vasculature. J Invest Dermatol 69: 154-166.

Taylor FW, Johnson JM, Kosiba WA, Kwain CM. 1989. Cutaneous vascular responses to isometric handgrip exercise. J Appl Physiol 66: 1586-1592. 